\title{
1D and 3D anthropometric data application on public transport vehicle layout and on oil and gas laboratories work environment design
}

\author{
Pastura $^{\mathrm{a},}$, F.C.H.; Guimarães ${ }^{\mathrm{a}}$, C.P; Zamberlan ${ }^{\mathrm{a}}$, M.C.P.; Cid ${ }^{\mathrm{a}}$, G.L.; Santos ${ }^{\mathrm{b}}$, V.S; Streit ${ }^{\mathrm{a}}$, P.; Paranhos ${ }^{\mathrm{a}}$, \\ A.G., Cobbe, R.T ${ }^{\mathrm{a}}$, Cobbe, K.T ${ }^{\mathrm{a}}$ and Batista, D. S. ${ }^{\mathrm{a}}$ \\ ${ }^{a}$ Divisão de Desenho Industrial, Instituto Nacional de Tecnologia (INT), Av. Venezuela 82, Térreo, Anexo 4, \\ Saúde, RJ, Rio de Janeiro, Brasil \\ ${ }^{\mathrm{b}}$ Pontifícia Universidade Católica do Rio de Janeiro - PUC-Rio. Rua Marquês de São Vicente, 225, Gávea, Rio \\ de Janeiro, RJ - Brasil - 22451-900
}

\begin{abstract}
The goal of this paper is to present 1D and 3D anthropometric data applied to two distinct design situations: one related to the interior layout of a public transport vehicle and another one related to oil and gas laboratories work environment design. On this study, the 1D anthropometric data were extracted from the Brazilian anthropometric database developed by INT and the 3D anthropometric data were obtained using a Cyberware 3D whole body scanner. A second purpose of this paper is to present the $3 \mathrm{D}$ human scanning data as a tool that can help designers on decision making.
\end{abstract}

Keywords: 1D anthropometry, 3D anthropometry, applied anthropometry, product and work environment design

\section{Introduction}

The application of anthropometric data to work space design can be done with direct use of one or two-dimensional measures or it can be done through the use of 3D digital human models (Bradtmiller et al., 2004; Green et al., 2011). On this study, 3D human scans (static 3D digital human models) were used to evaluate the three-dimensional space occupied by users and workers on two design situations: an interior layout of a public transport vehicle and laboratories work environment design. For that reason, people were scanned simulating real postures adopted in the subway, on the public transport vehicle case, and simulating working postures, on the oil and gas laboratories case. ${ }^{*}$

\section{First design situation - Public transport vehicle interior lay-out}

This project was conducted by UFRJ (Federal University of Rio de Janeiro), INT and Ergon Projetos (an ergonomics design Brazilian company) for defining the interior layout of a modular vehicle that uses magnetic levitation technology for public transport. One of the main layout aspects was to establish the number of people for each vehicle's module. That was an important issue because it determined the vehicle's modules final weight that

\footnotetext{
* Corresponding author. Email: flavia.pastura@int.gov.br
} 
was directly related to the magnetic levitation capacity. To establish that one-dimensional and three-dimensional anthropometry approaches were used. In comparing both approaches, the 3D showed more appropriate answers when the maximum amount of people was the variable wanted and also in determining airflow system and space volumes occupied by different sets of people. The 1D anthropometry was used, for example, on studies regarding reaching height of handrails.

\subsection{Passenger occupation and vehicle's modules dimensions analysis}

In order to study passenger occupation and vehicle's modules dimensions adequacy, 2D AUTOCAD drawings were elaborated from data and drawings provided by client and 1D anthropometric measurements from the Brazilian Population Anthropometric Database were applied to the AUTOCAD drawings (see figure 1).

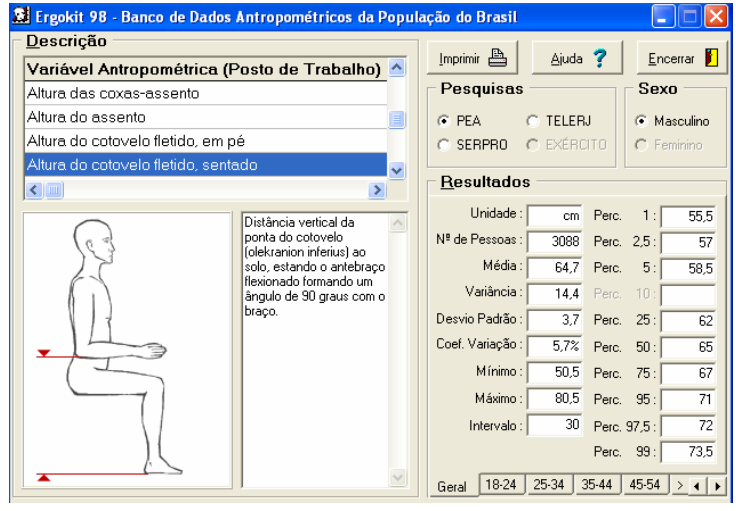

Fig. 1. Brazilian Population Anthropometric Database (Instituto Nacional de Tecnologia / Ministério da Ciência e Tecnologia).

\subsubsection{Dimensional study of passenger module (seat cabin) and door module}

The dimensional study considered the data provided by client: vehicle's modules dimensions $230 \mathrm{~cm}$ (width) $\mathrm{x} 102,5 \mathrm{~cm}$ (length); maximum weight of each module with passengers - $800 \mathrm{Kg}$; expected capacity - 08 passengers for each module; and $1 \mathrm{D}$ anthropometric measurements $\left(95^{\text {th }}\right.$ male shoulder breadth and $95^{\text {th }}$ male buttock-feet length) that were applied to 2D AUTOCAD drawings (see figure 2).
Considering the modules layout client conception seats placed sideways facing inward - and double passenger cabin, the maximum occupation would be 12 people, 08 on sitting posture and 04 on standing posture. The distance between passengers' feet on sitting posture (around $34 \mathrm{~cm}$ ) isn't enough for standing passengers, imperiling their balance and also generating the need to change the sitting passenger's feet position (see figure 3).
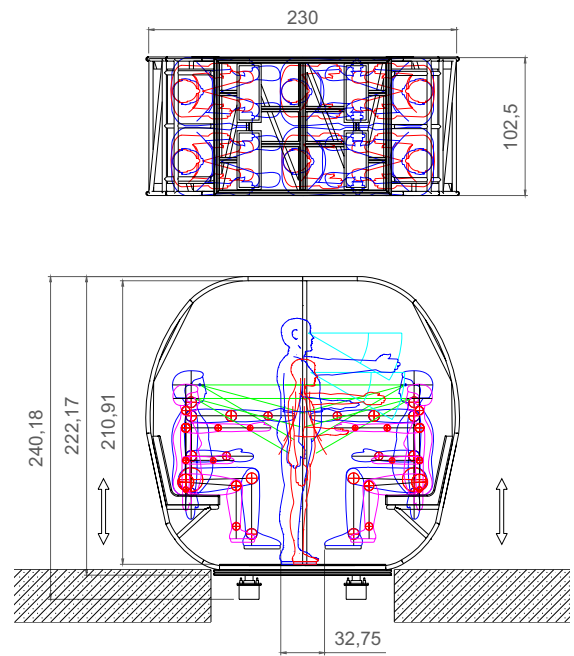

Fig. 2. 1D anthropometric measurements applied to 2D AUTOCAD drawings. Passenger module (seat cabin) dimensional evaluation

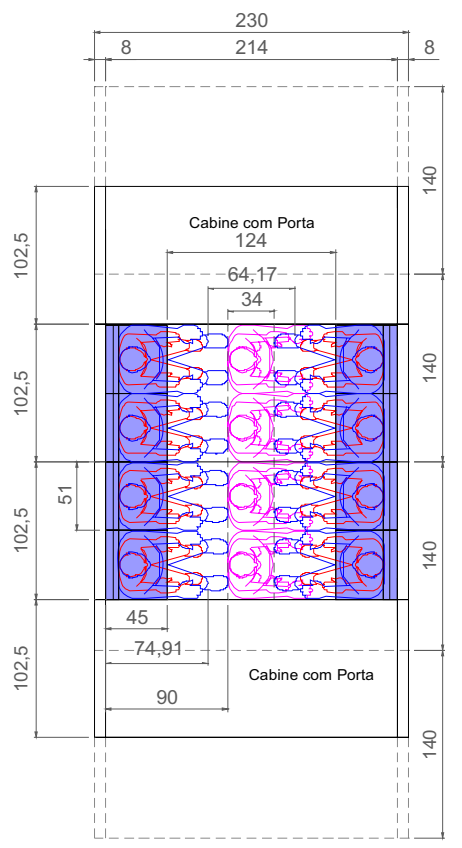

Fig. 3. passengers' maximum occupation considering client's conception 


\subsection{Interior layout alternatives study}

Three layout alternatives (A, B and C) were presented taking into account:

- Occupation by people with different sizes and proportions;

- Access doors: entering and leaving the vehicle should consider 1,20 m opening;

- Circulation inside the vehicle (compressed spaces and people flow issues)

- Different postures adoption so that people's head could be maintained at different levels to avoid confinement feeling and to facilitate air-conditioning flow inside passenger cabin.

\subsubsection{Applying scanned human models}

The use of a laser body scanner (see figure 4) allowed creating static 3D virtual models of users in different postures wearing different accessories like backpackers, bags, etc. These virtual models (see figure 5) were used in the interior layout and occupation study.

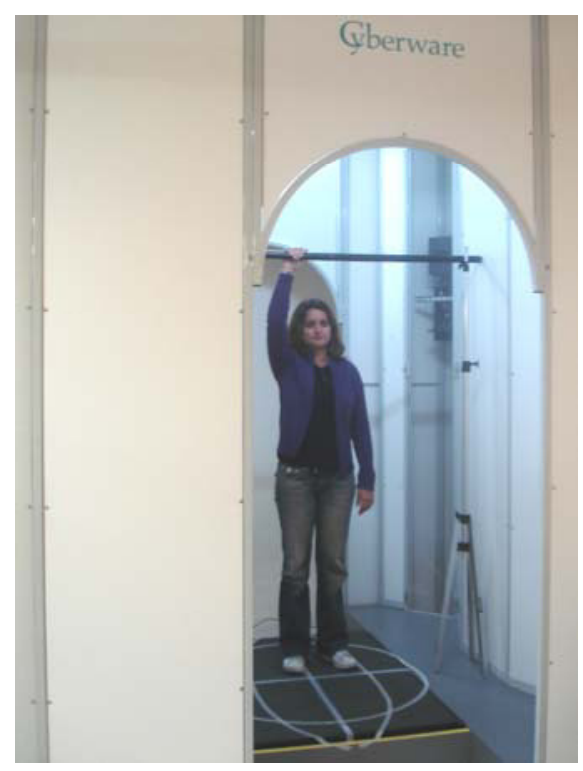

Fig. 4. Scanning subject holding a bar positioned as a handrail

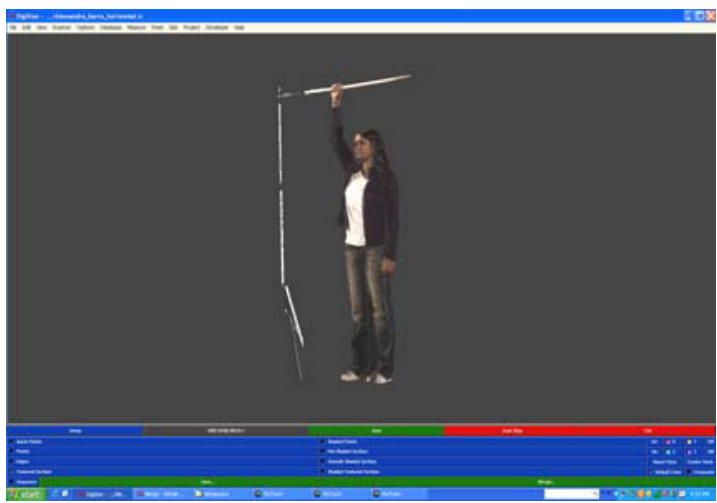

Fig. 5. Scanned human model (static 3D virtual model)

\subsubsection{Alternative A interior layout}

In the layout alternative $\mathrm{A}$ it was possible to place, in a comfortable way, 4 seated people $\left(95^{\text {th }}\right.$ male shoulder breadth $), 10$ semi-seated $\left(5^{\text {th }}\right.$ female shoulder breadth) and 10 standing in a total of 24 people, as shown in figure 6 .

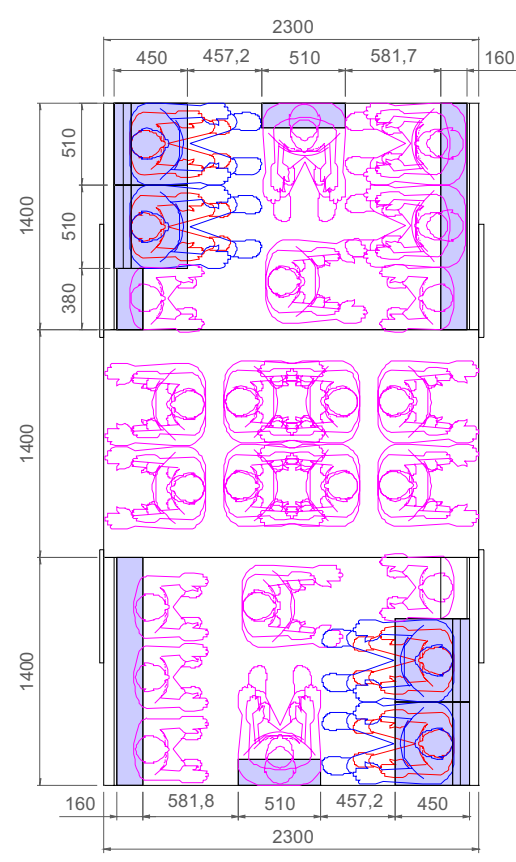

Fig. 6. Alternative A interior layout 
2.2.3 Alternative A occupation study using static $3 D$ virtual models

Considering alternative A, a 3D virtual mockup was generated and 3D static virtual models applied to it. It was observed that alternative A couldn't fit 24 people as the 2D layout study had demonstrated. It could only fit 20 users positioned as shown in figures 7 and 8 .

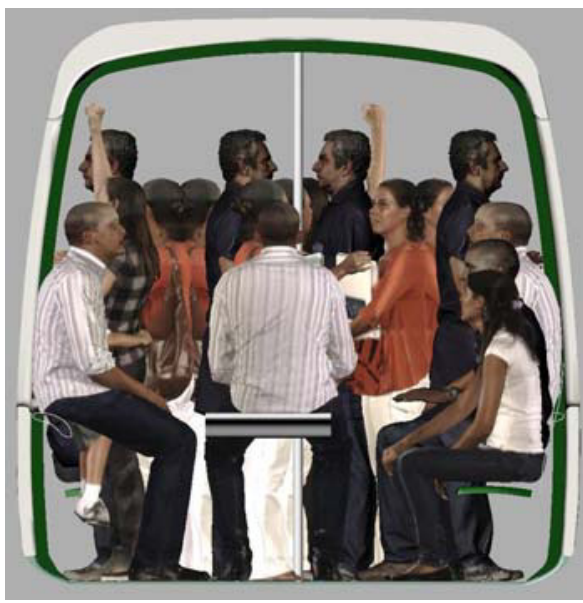

Fig. 7. Alternative A occupation study with 3D human scans

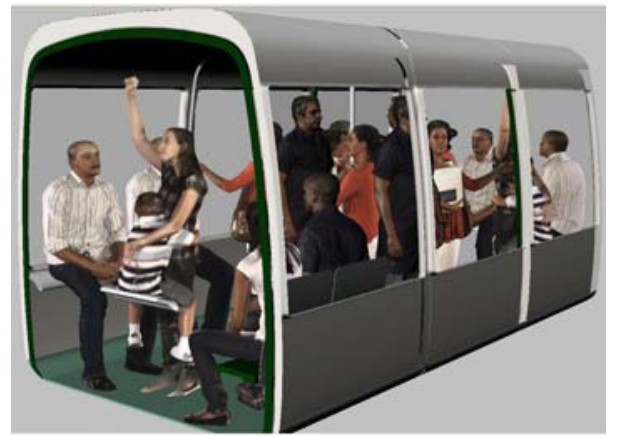

Fig. 8. Alternative A occupation study with 3D human scans

\subsubsection{Alternative B interior layout}

In the layout alternative B it was possible to place, in a comfortable way, 2 seated people, 12 semiseated and 12 standing, in a total of 26 people, as shown in figure 9.

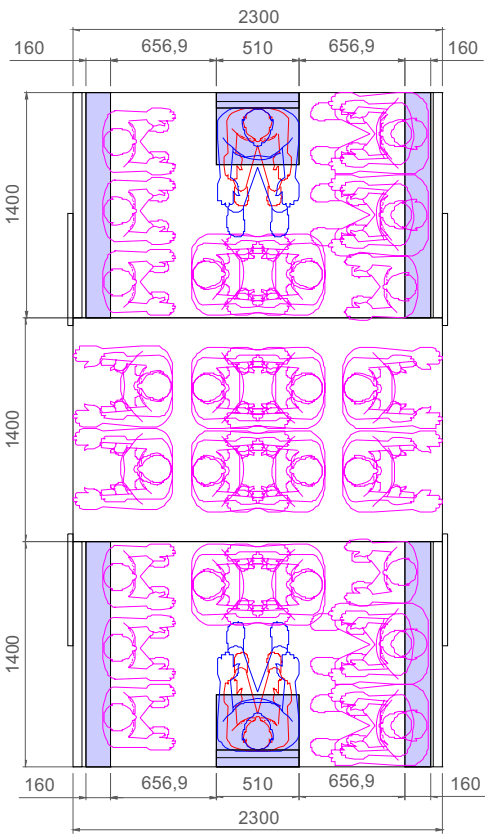

Fig. 9. Alternative B interior layout

2.2.5 Alternative B occupation study using static $3 D$ virtual models

Considering alternative $\mathrm{B}$, a 3D virtual mockup was generated and 3D static virtual models applied to it. It was concluded that alternative B couldn't fit 26 people as the 2D layout study had showed but just 22 users (see figures 10 and 11).

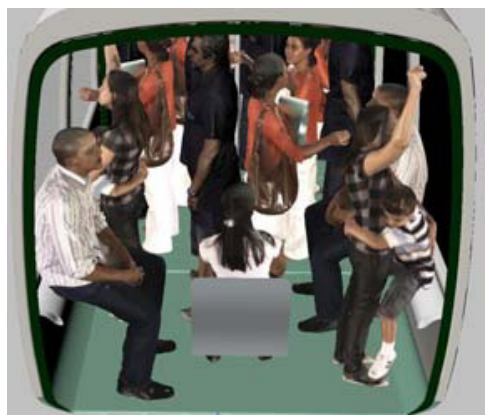

Fig. 10. Alternative B occupation study with 3D human scans 


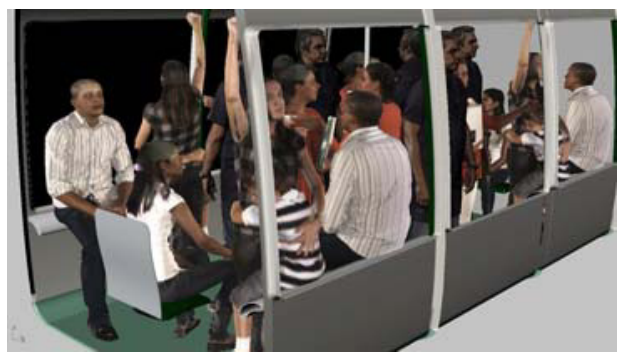

Fig. 11. Alternative B occupation study with 3D human scans

\subsubsection{Alternative C interior layout}

In the layout alternative $\mathrm{C}$ it was possible to place, 6 seated users, 6 semi-seated and 14 standing, in a total of 26 people, as shown in figure 12 .

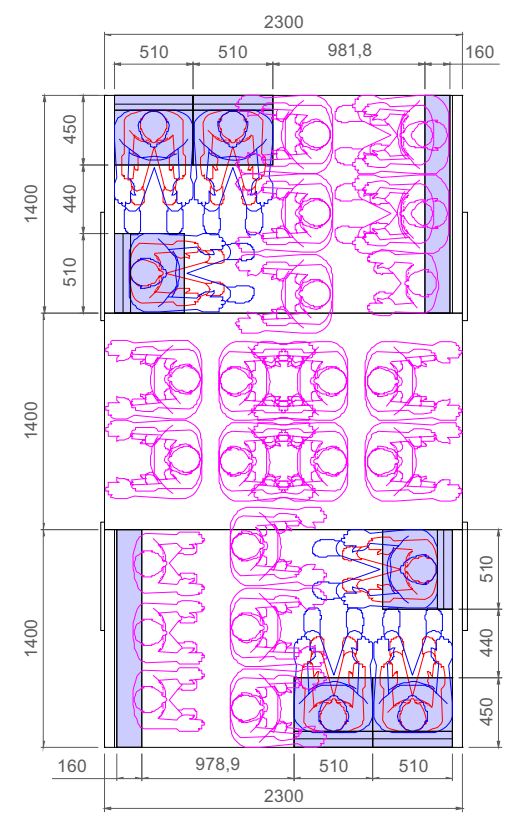

Fig. 12. Alternative $\mathrm{C}$ interior layout

\subsubsection{Alternative C occupation study using static $3 D$ virtual models}

Considering alternative $\mathrm{C}$, it was observed that it couldn't fit 26 people as the 2D layout study had presented, but 22 users (see figures 13 and 14).

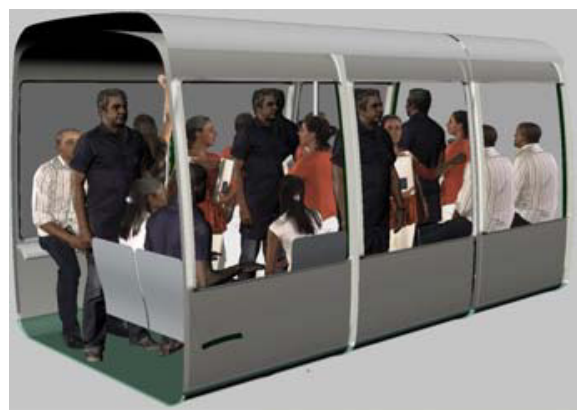

Fig. 13. Alternative $\mathrm{C}$ occupation study with $3 \mathrm{D}$ human scans

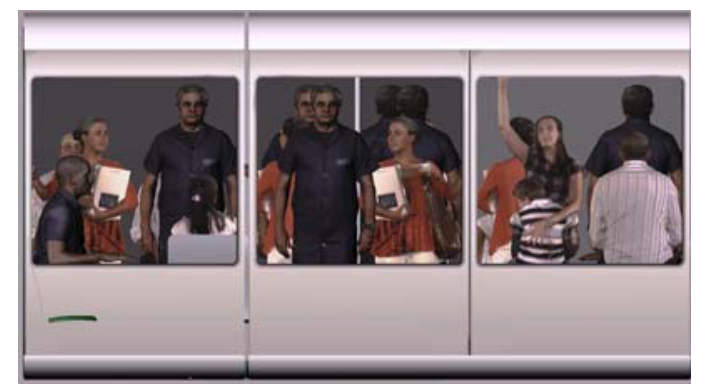

Fig. 14. Alternative C occupation study with 3D human scans

\subsection{Maximum Occupation Study}

In order to help modules' size definition, a maximum occupation study was done considering the $95^{\text {th }}$ male and $5^{\text {th }}$ female shoulder breadth extracted from the Brazilian Population Anthropometric Database. These measurements were applied to the three interior layout alternatives shown before. According to maximum occupation study it was possible to estimate the module weight taking into account the $95^{\text {th }}$ male weight value $-85,9 \mathrm{Kg}$ - and the $5^{\text {th }}$ female weight value $-43,7 \mathrm{Kg}$.

\subsubsection{Alternative A interior layout}

In alternative $\mathrm{A}$ it was possible to fit, the maximum number of 61 of $5^{\text {th }}$ female shoulder breadth, with a total weight of $2.665,7 \mathrm{Kg}$ for three vehicle modules, in other words $888,5 \mathrm{Kg}$ per vehicle. Considering the $95^{\text {th }}$ male shoulder breadth, the maximum number was 34 , with a total weight of $2.920,6 \mathrm{Kg}$ for the three modules, in other words $973,5 \mathrm{Kg}$ per vehicle (see figure 15). 

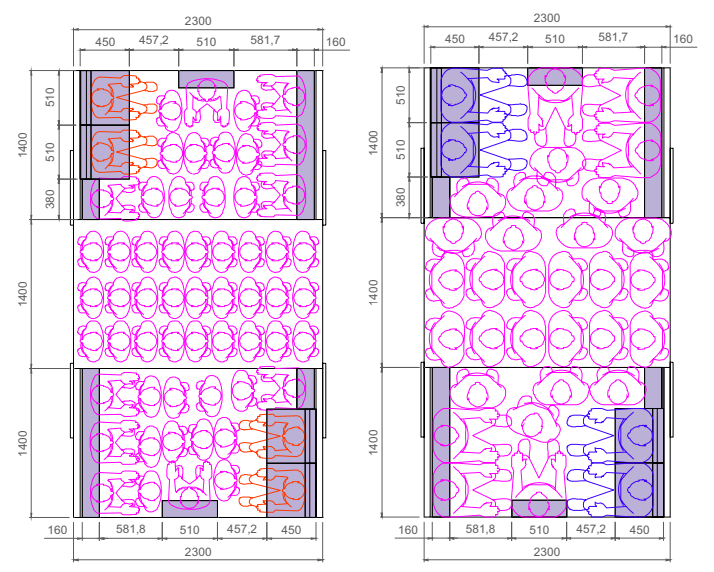

Fig. 15. Alternative A - maximum occupation study

\subsubsection{Alternative B interior layout}

In alternative $B$ it was possible to fit, the maximum number of 69 of $5^{\text {th }}$ female shoulder breadth, with a total weight of $3.015,3 \mathrm{Kg}$ for three vehicle modules, in other words $1005 \mathrm{~kg}$ per vehicle. Considering the $95^{\text {th }}$ male shoulder breadth, the maximum number was 34 , with a total weight of $2.920,6 \mathrm{Kg}$ for three modules, in other words, near $973,5 \mathrm{Kg}$ per vehicle (see figure 16).
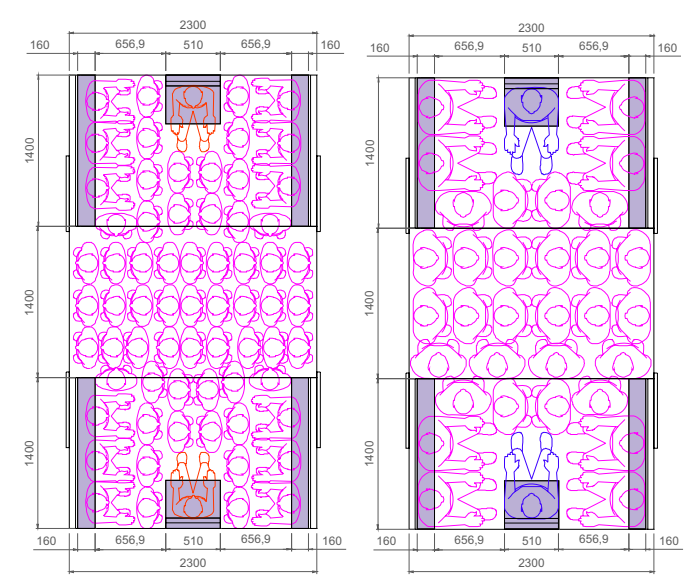

Fig. 16. Alternative B - maximum occupation study

\subsubsection{Alternative C interior layout}

In alternative $\mathrm{C}$ it was possible to fit, the maximum number of 59 of $5^{\text {th }}$ female shoulder breadth, with a total weight of $2.578,3 \mathrm{Kg}$ for three modules, in other words $859,4 \mathrm{Kg}$ per vehicle.

Considering the $95^{\text {th }}$ male shoulder breadth the maximum number was 32 , with a total weight of $2.748,8 \mathrm{Kg}$ for three modules, in other words 916,2 $\mathrm{Kg}$ per vehicle (see figure 17).
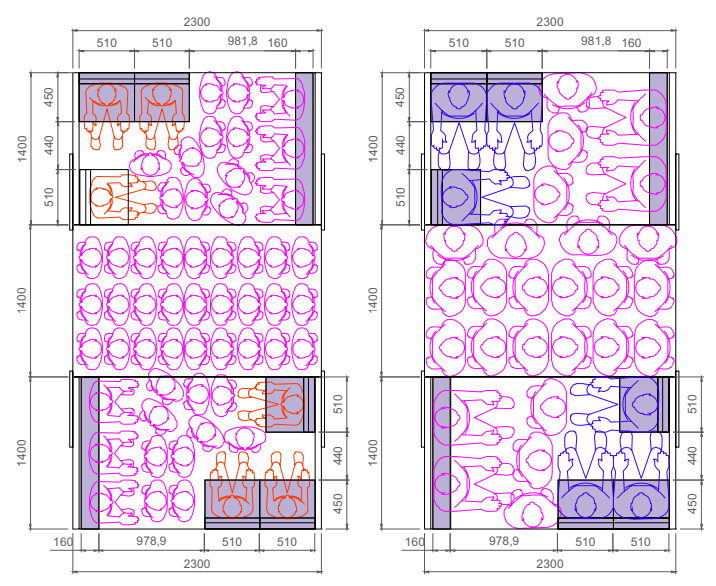

Fig. 17. Alternative C - maximum occupation study

As conclusion, weight will never be constant and may vary between $859,4 \mathrm{Kg}$ and $1005 \mathrm{Kg}$ per vehicle, considering $95^{\text {th }}$ male and $5^{\text {th }}$ female weight values taken as reference for the occupation study. That study should also consider the weight of personal belongings like backpacks (5 Kg average per person).

There are ways of controlling horizontal occupation (more and more people coming in) but never vertical occupation (stature of people to be transported). So weight reference is essential on defining the developed system robustness.

There isn't a conclusion about the interior layout yet because changes were made in modules dimensions that demand new studies. But it is important to say that the use of $3 \mathrm{D}$ human scans is being essential in the layout definition, making the cabin occupation visualization more precise.

When 3D human scans (3D static virtual models) were applied to the $3 \mathrm{D}$ virtual mockups it was possible to see that the solutions proposed by $1 \mathrm{D}$ measurement - shoulder breadth - lead to a bigger number of passengers. 


\section{Second design situation - Oil and gas laboratories work environment design}

A cooperation term between INT and CENPES Petrobras Research Center - was established to conduct an ergonomic design study for new oil and gas laboratories. In this study 1D anthropometric measurements were applied to set work environment dimensions. For example, to establish the level of a work surface for oil samples characterization, the key dimension used was the $5^{\text {th }}$ percentile female elbow height (see figure 18).

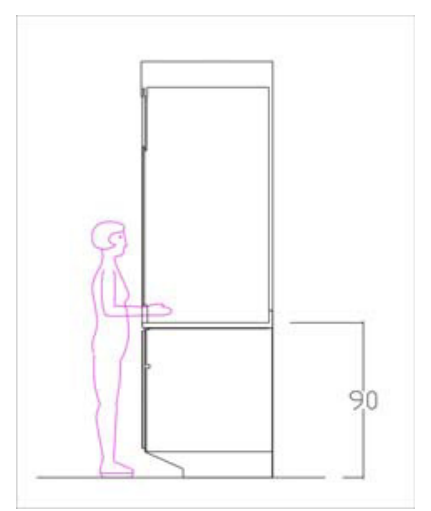

Fig 18. Work surface level for oil samples characterization

To establish the work surface level for specific equipments, like chromatographs, the dimensions used were the $5^{\text {th }}$ percentile female elbow height for the minimum height and the $95^{\text {th }}$ percentile male elbow height for the maximum height (see figure 19). In that case, the work surface level needed to be adjustable considering the operator elbow height.

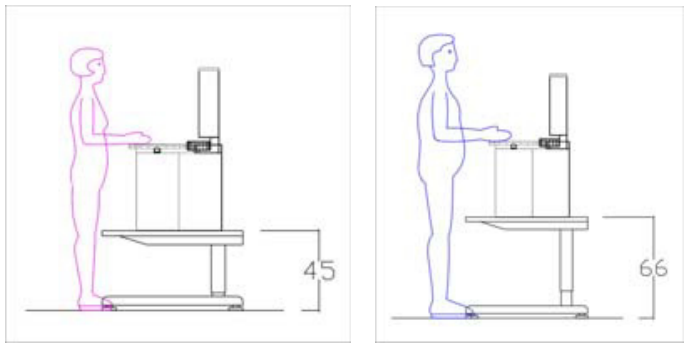

Fig. 19. work surface level for chromatographs
The 3D anthropometry was used to develop animated 3D digital human models (DHM). These models were used on simulations of virtual work environments (scenarios) that represent the proposed design for the new laboratories.

With those simulations, technicians were able to visualize themselves in virtual work environment as well as their colleagues and were able to evaluate equipments, furniture and workstation positioning according to their real work activities.

Drawing a comparison between 1D and 3D anthropometry approaches it was possible to see that 3D anthropometric data associated to human motion capture allowed virtual representation of working postures and movements (e.g. squatted down) that permitted better comprehension on people's workflow (see figures 20 e 21).

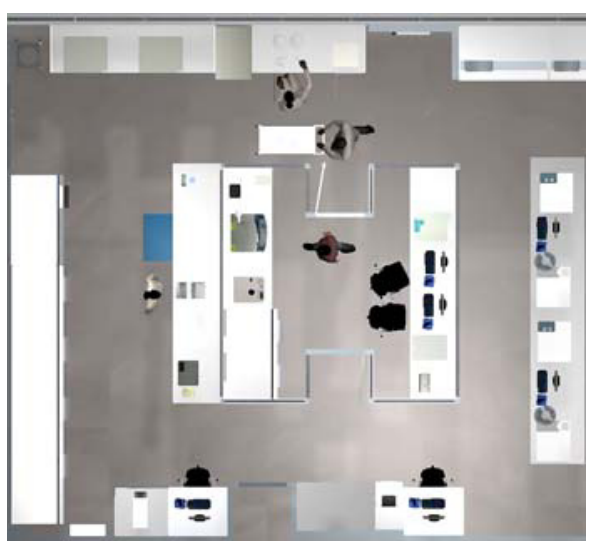

Fig. 20. Virtual work environment simulation with 3D DHMs animated from motion capture

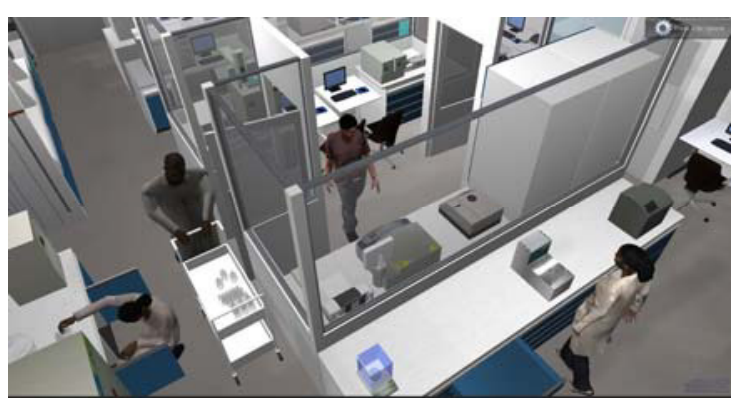

Fig. 21. Virtual work environment simulation with 3D DHMs animated from motion capture 


\section{Conclusion}

INT's ergonomics laboratory has been storing static 3D digital human models based on 3D people scanning in functional postures, related to work activities, and ordinary postures adopted in daily life activities in order to develop a human posture database that can be applied in ergonomic design studies. The 3D digital human models application on the studied design situations demonstrated to be an important tool on designers' decision making. It allowed virtual visualization of new solutions for the design problems.

On both design situations presented, two approaches were conducted: 1) a traditional one, applying 1D anthropometric data on technical drawings (top, side and front views) and 2) applying human scanning results on virtual scenarios (Pastura, et al., 2010). The results showed that $1 \mathrm{D}$ and $3 \mathrm{D}$ anthropometric data can be complementary on solving dimensional problems and on establishing design solutions.

\section{References}

[1] Green, R.F.; Hudson. J. A; method for positioning human models in airplane passenger seat. Advances in Applied Digital Human Modeling, edited by Duffy, G. Vincent, 2011.

[2] Bradtmiller, B.; Gordon, C.C.; Kouchi, M.; Jürgens, H. W.; LEE, Y; Traditional Anthropometry, In Working Postures and Movements: tools for evaluation and engineering, edited by Nico J. Delleman, Christine M. Haslegrave and Don B. Chaffin, 2004.

[3] Robinette, M.K.; Daanen, H. A.M.; Zehner, G. F.; ThreeDimensional Anthropometry, In Working Postures and Movements: tools for evaluation and engineering, edited by Nico J. Delleman, Christine M. Haslegrave and Don B. Chaffin, 2004

[4] Pastura, F.H et al. 3D Laser scanning technology applied to ergonomics projects, WEAR Valencia, 2010.

[5] ERGOKIT - Banco de Dados Antropométricos da População Brasileira, Instituto Nacional de Tecnologia - INT / Ministério da Ciência e Tecnologia - MCT, 1995 